\title{
Online tool helps future MDs plan their careers
}

$\mathrm{C}$ anada's medical faculties have developed a new online careercounselling tool to answer questions about everything from residents' salaries to what exams international medical school graduates must pass to get a residency spot.

Future MD Canada is aimed at current and aspiring medical students, international medical graduates, residents and those who teach them. The Association of Faculties of Medicine of Canada (AFMC), which represents the country's 17 medical schools, created the bilingual website in response to a recommendation from the Physician Resource Planning Task Force. The Conference of Deputy Ministers of Health convened the task force in 2013 to help with resource planning in the health care sector.

The AFMC was the natural host for the site given its role in supporting current and potential medical students, says Dr. Geneviève Moineau, AFMC president and CEO and co-chair of the task force. "We do think there's a tremendous amount of valuable information for those learners in this."

Although the site does not include specific information about which areas of Canada need particular specialists, it does note that some "large Canadian cities are oversaturated with certain specialties, while some smaller communities simply cannot offer certain practice opportunities." It also advises those considering careers as doctors "to take these realities into account" when considering their choices of specialties and the locations of their practices.

To clarify misconceptions, the Future MD site states that "those who complete MD training outside of this country have no guarantee of securing a training position in Canada, let alone in their desired specialty or practice location." Providing information for Canadians who choose to study abroad about how the process works in Canada was a priority for the task force, says Moineau, because this is an area that causes grief for governments and politicians.

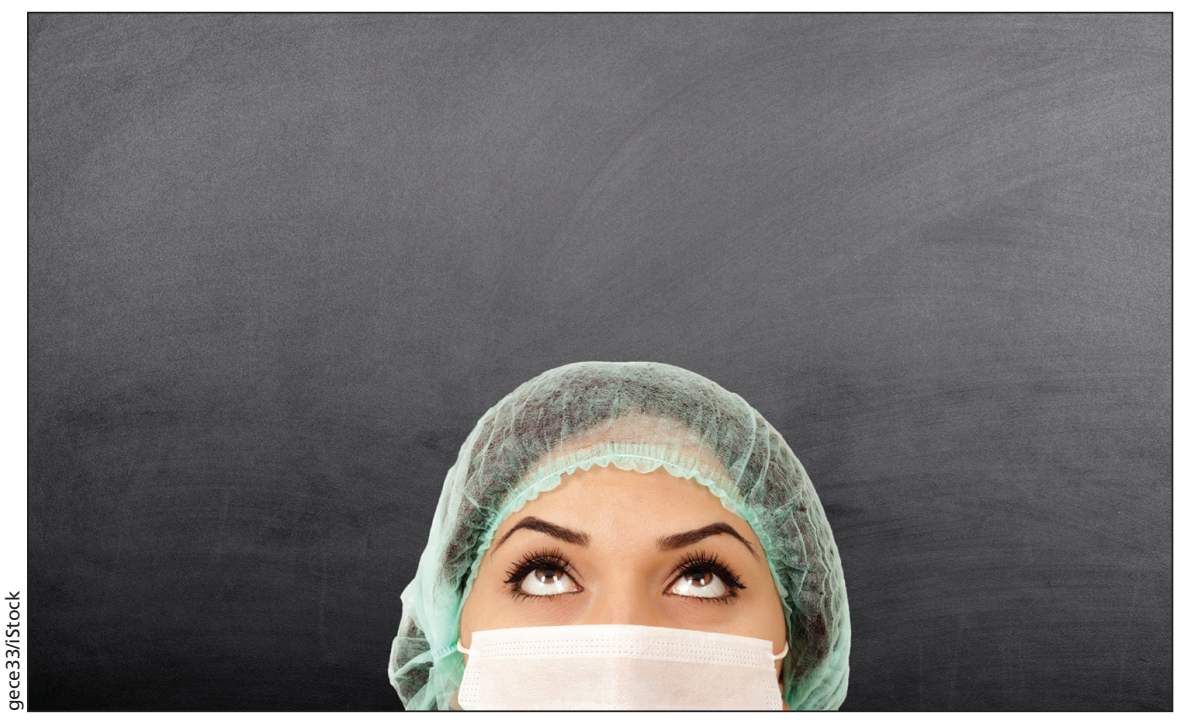

Future MD Canada is a one-stop information site for Canada's future physicians.

The site provides information for international graduates about applying for residency training, the chances of obtaining a residency spot and how to get a licence to practise in Canada if they qualified abroad. The truly eager can even download the entire 74-page document that contains each of the questions and answers the website supplies.

The idea behind Future MD is to centralize information that was previously available in piecemeal fashion, says Anthea Lafreniere, president-elect of the Canadian Federation of Medical Students (CFMS). "It's really a tool for anyone interested in medicine at any of the entry points."

Lafreniere, who is entering her fourth year at the University of Ottawa, recalls relying on word of mouth and her colleagues' knowledge when she was applying for residency matches. Future MD is well on its way to being a good starting point for anyone considering whether to pursue a medical career, she says.

She would like the site to eventually add "a robust analysis" of the health care workforce in Canada to help future doctors choose their specialties by considering not only where the jobs will be but where critical physician shortages exist.

"I think the information that truly serves society is getting the right kinds of doctors in the right places. Evidencebased career decisions are critical," Lafreniere says.

If more accurate data emerge about specific resource needs in each province, the AFMC will add it, says Moineau. Currently, there are not enough accurate data, she added.

Dr. Melanie Bechard, a pediatrics resident at The Hospital for Sick Children, Toronto, wishes the information that Future MD offered had been available before she entered medical school. "As somebody who entered medicine from a family without any other physicians in it, I like that it provides very clear information on the pathway to medical school," says Bechard, who reviewed the site for Resident Doctors of Canada and CFMS. "There are a number of requirements at every stage - and depending on your personal connections, there can be huge disparities about what you know."

She hopes the site will eventually include even more specific content about the common factors that help students get into medical school, such as having research experience. - Laura Eggertson, Ottawa

CMAJ 2015. DOI:10.1503/cmaj.109-5123 